\title{
Colocalized neurotransmitters in the hindbrain cooperate in adaptation to chronic hypernatremia
}

\author{
Rita Matuska ${ }^{1}$ - Dóra Zelena ${ }^{2,3} \cdot$ Katalin Könczöl ${ }^{4} \cdot$ Rege Sugárka Papp ${ }^{5} \cdot$ Máté Durst $^{4} \cdot$ Dorina Guba $^{4}$. \\ Bibiana Török $^{2,6} \cdot$ Peter Varnai ${ }^{1} \cdot$ Zsuzsanna E. Tóth $^{4}$ (1)
}

Received: 17 June 2019 / Accepted: 13 February 2020 / Published online: 21 March 2020

(c) The Author(s) 2020

\begin{abstract}
Chronic hypernatremia activates the central osmoregulatory mechanisms and inhibits the function of the hypothalamic-pituitary-adrenal (HPA) axis. Noradrenaline (NE) release into the periventricular anteroventral third ventricle region (AV3V), the supraoptic (SON) and hypothalamic paraventricular nuclei (PVN) from efferents of the caudal ventrolateral (cVLM) and dorsomedial (cDMM) medulla has been shown to be essential for the hypernatremia-evoked responses and for the HPA response to acute restraint. Notably, the medullary NE cell groups highly coexpress prolactin-releasing peptide (PrRP) and nesfatin-1/NUCB2 (nesfatin), therefore, we assumed they contributed to the reactions to chronic hypernatremia. To investigate this, we compared two models: homozygous Brattleboro rats with hereditary diabetes insipidus (DI) and Wistar rats subjected to chronic high salt solution (HS) intake. HS rats had higher plasma osmolality than DI rats. PrRP and nesfatin mRNA levels were higher in both models, in both medullary regions compared to controls. Elevated basal tyrosine hydroxylase (TH) expression and impaired restraint-induced TH, PrRP and nesfatin expression elevations in the cVLM were, however, detected only in HS, but not in DI rats. Simultaneously, only HS rats exhibited classical signs of chronic stress and severely blunted hormonal reactions to acute restraint. Data suggest that HPA axis responsiveness to restraint depends on the type of hypernatremia, and on NE capacity in the cVLM. Additionally, NE and PrRP signalization primarily of medullary origin is increased in the SON, PVN and AV3V in HS rats. This suggests a cooperative action in the adaptation responses and designates the AV3V as a new site for PrRP's action in hypernatremia.
\end{abstract}

Keywords Prolactin-releasing peptide $\cdot$ Noradrenaline $\cdot$ Nesfatin- $1 \cdot$ Restraint $\cdot$ Brattleboro rat $\cdot$ Stress

Zsuzsanna E. Tóth

toth.zsuzsanna.emese@med.semmelweis-univ.hu

1 Department of Physiology, Semmelweis University, Budapest, Hungary

2 Behavioral Neurobiology, Institute of Experimental Medicine, Budapest, Hungary

3 Centre for Neuroscience, Szentágothai Research Centre, Institute of Physiology, Medical School, University of Pécs, Pécs, Hungary

4 Department of Anatomy, Histology and Embryology, Semmelweis University, Budapest, Hungary

5 Human Brain Tissue Bank and Microdissection Laboratory, Semmelweis University, Budapest, Hungary

6 Janos Szentagothai School of Neurosciences, Semmelweis University, Budapest, Hungary

\section{Introduction}

Homeostatic regulation of plasma osmolality $(275-290 \mathrm{mOsm} / \mathrm{kg})$ is vital. Elevated osmolality develops primarily based on elevated extracellular $\left[\mathrm{Na}^{+}\right]$level known as hypernatremia. Besides activating the central osmoregulatory system, hypernatremia also represents a serious stress for the organism that impairs the response of the hypothalamic-pituitary-adrenal (HPA) axis to a novel acute stressor (Amaya et al. 2001; Krause et al. 2017). The mechanism is still unclarified, therefore we focused our research on brain structures that participate in the control of both hypernatremia and stress-evoked responses, such as the A1 and A2 noradrenaline (NE) cell groups in the caudal ventrolateral (cVLM) and dorsomedial (cDMM) medulla oblongata.

Hypertonic saline administered by intravenous infusion evokes neuronal activation (Fos positivity) in the A1 and A2 NE cells specifically, as infusions of physiological 
or hypotonic $\mathrm{NaCl}$ solutions fail to activate these neurons (Hochstenbach and Ciriello 1995). NE is an essential transmitter for stimulating areas in the hypothalamus that govern the neuroendocrine, autonomic and behavioral responses for hypernatremia (Day 1989; Tanaka et al. 1997; Huang et al. 2000; Bourque 2008; Pedrino et al. 2012; da Silva et al. 2013; Sawchenko and Swanson 1981; Pacak et al. 1995). These areas receive their NE innervation primarily from the neurons of the A1, A2 cell groups and include the paraventricular (PVN) and supraoptic (SON) nuclei as well as the periventricular anteroventral third ventricle region $(\mathrm{AV} 3 \mathrm{~V})$. The latter comprises the organum vasculosum laminae terminalis (OVLT), the median preoptic nucleus (MnPO) and the preoptic and anteroventral periventricular nuclei (Bourque 2008; Menani et al. 2014).

The neurons of the A1, A2 cell groups also convey stress-related stimuli that signal homeostatic perturbations (Liposits et al. 1986; Ulrich-Lai and Herman 2009; Gaillet et al. 1991) towards the HPA axis, namely towards the corticotropin-releasing hormone ( $\mathrm{CRH})$ producing cells in the parvocellular PVN. The PVN is innervated by NE fibers almost exclusively (94\%) from the A1 and A2 cell groups (Sawchenko and Swanson 1981, 1982). Bilateral pharmacological lesions of the ascending medullary NE fibers lead to a $90 \%$ decrease of CRH released into hypophyseal portal vessels (Guillaume et al. 1987) and obliteration of the diurnal increment in plasma adrenocorticotropic hormone (ACTH) (Szafarczyk et al. 1985) under basal conditions. Similar lesions caused dramatically reduced ACTH and impaired corticosterone responses to acute ether or restraint stress (Gaillet et al. 1991; Pacak et al. 1995). Chemical ablation of the catecholaminergic terminals within the PVN also attenuated peak ACTH and corticosterone levels in response to acute restraint (Flak et al. 2014).

Despite these facts, the significance of the A1 and A2 cells in adaptation to chronic hypernatremia as well as in altered responsiveness of the HPA axis to acute restraint in hypernatremic animals has not been elucidated yet. Moreover, the A1 and A2 cells very intensely coexpress prolactin-releasing peptide (PrRP) and nesfatin-1/NUCB2 (nesfatin) (Chen et al. 1999; Toth et al. 2008; Konczol et al. 2010) together with NE. Therefore, we assume that cooperation of these substances may be relevant. Indeed, enhanced expression of different cotransmitters is a fundamental event in adaptation to chronic restraint stress (Ma et al. 1997; Amaya et al. 2001; Toth et al. 2008). PrRP cells comprise a large subpopulation of the A2 cells $(\sim 82 \%)$ in the nucleus of the solitary tract (NTS) and practically correspond to all A1 ( 98\%) neurons. They, therefore, coexpress tyrosine hydroxylase (TH, the ratelimiting enzyme of the NE synthesis) and PrRP (Chen et al. 1999; Toth et al. 2008). This feature helps to identify PrRP axons of medullary origin at the terminal fields, as the third PrRP cell population in the brain, which exists in the dorsomedial nucleus of the hypothalamus, is $\mathrm{TH}$ negative (Roland et al. 1999). PrRP is involved in various functions challenged by hypernatremia, like the cardiovascular regulation (Yamada et al. 2009) and the control of oxytocin (promotes sodium excretion) and vasopressin (AVP, stimulates water retention) release from the magnocellular cells of the SON and PVN (Maruyama et al. 1999; Uchida et al. 2010). PrRP neurons in the A1 and A2 cell groups are strongly activated ( $90 \%$ Fos positivity) by water immersion-restraint stress, while PrRP-negative A2 neurons barely respond to this stimulus (Maruyama et al. 2001). Acute restraint upregulates PrRP mRNA expression of the A1 cell group (Mera et al. 2006; Konczol et al. 2010). PrRP cells synapse with CRH neurons in the PVN and central administration of PrRP induces Fos protein accumulation in $\mathrm{CRH}$ neurons as well as a CRH-mediated increase in the ACTH level (Seal et al. 2002; Maruyama et al. 2001). Although a synergistic effect of PrRP and NE was observed on ACTH (Maruyama et al. 2001) and AVP releases (Uchida et al. 2010), the contribution of PrRP to chronic hyperosmotic responses in the PVN, SON and AV3V has not been investigated yet and the origin of the PrRP fibers at these locations is unrevealed.

Nesfatin-1, the N-terminal fragment of the NUCB2 prohormone is expressed in several brain nuclei, for example, in the PVN and SON (Foo et al. 2008). The vast majority of the nesfatin neurons in the CVLM and cDMM are TH and PrRP coexpressing cells (Konczol et al. 2010). Nesfatin is not transported axonally, but acts locally by autocrine/paracrine fashion (Foo et al. 2008). Nesfatin has been attributed to similar autonomic and endocrine functions to PrRP (Konczol et al. 2010; Maejima et al. 2009; Yilmaz et al. 2015; Yosten and Samson 2009). As these effects were revealed by intracerebroventricular (icv) injections, the exact sites of actions are unknown. We earlier found, however, that acute restraint elevated nesfatin expression in the CVLM indicating its role in the stress response (Konczol et al. 2010).

Based on the above facts, we addressed the following questions: 1 , whether the level of the stress caused by chronic hypernatremia may depend on the type of hypernatremia (i.e., eu- or hypervolemic, congenital or acquired); 2 , whether the different types of chronic hypernatremia affect the responsiveness to acute restraint differentially; and 3, whether the expression of TH, PrRP and nesfatin in the cDMM and cVLM reflects the actual sensitivity of the HPA axis to acute restraint under chronic hypernatremic conditions. Additionally, we also examined the morphological basis for a putative interaction of NE and PrRP of medullary origin in the hypothalamus (PVN, SON, AV3V) in response to chronic hypernatremia. We used two kinds of models: (1) Brattleboro rats homozygous for diabetes insipidus (euvolemic, DI rats) due to hereditary AVP deficiency and (2) 
Wistar rats receiving high salt $(2 \% \mathrm{NaCl})$ solution instead of tap water (hypervolemic, HS rats) for 6 days.

\section{Methods}

\section{Animals}

The subjects of the study were adult (12-14 week old) male Wistar (Toxi-Coop Toxicological Research Center Zrt, Dunakeszi, Hungary) and homozygous Brattleboro rats (+/+ wild type; WT and -/- AVP deficient with diabetes insipidus; DI). The Brattleboro rats were maintained in a colony started from breeder rats from Harlan (Indianapolis, IN), as earlier described (Varga et al. 2016). The rats were housed in a controlled environment $\left(23 \pm 1{ }^{\circ} \mathrm{C}, 50-70 \%\right.$ humidity, $12 \mathrm{~h}$ light starting at 07:00) and had free access to standard rodent chow and tap water, except otherwise indicated. Due to the extremely high level of urination caused by the diabetic condition, we changed sawdust bedding daily for all rats. Animals were anesthetized with ketamine $(75 \mathrm{mg} /$ bwkg) (Richter Gedeon Nyrt., Budapest, Hungary) and xylasine $(15 \mathrm{mg} / \mathrm{bwkg})$ (CP-Pharma, Burgdorf, Germany) given intramuscularly prior to perfusion fixation.

\section{Experimental design}

\section{Experiment 1}

The Brattleboro rats were divided into four groups: WT-control, DI-control, WT-restraint (R) and DI-R ( $n=7 /$ group). Bodyweight, food and water intake of rats were recorded daily in the morning for 5 consecutive days before the experiment started.

The Wistar rats were also assigned into four experimental groups: normal salt (NS)-control, high salt (HS)-control, NS-R and HS-R ( $n=8 /$ group). Animals in the HS groups received 2\% $\mathrm{NaCl}$ solution instead of tap water for 6 days. Bodyweight, daily food and water intake of rats were measured on every 3rd day (starting on day zero) to minimize extra stress.

On the day of the experiments, all animals in the R groups were subjected to a single restraint stress as described below. Control subjects remained in their home cages. Blood from the tail vein was collected for hormonal measurements 1 $h$ after restraint had started both from stressed and nonstressed animals. At the end of the restraint, all animals were sacrificed by decapitation. The thymi and adrenal glands were dissected out and their weights were measured. The brains were removed, frozen on dry ice and used for in situ hybridization histochemistry.

\section{Experiment 2}

The Wistar rats were assigned to two experimental groups, $\mathrm{NS}$ and HS ( $n=8$ /group). Animals in the HS group received $2 \% \mathrm{NaCl}$ solution instead of tap water for 6 days. At the end, animals were sacrificed either by decapitation ( $n=4 /$ group) or by transcardial perfusion with $4 \%$ paraformaldehyde in $0.1 \mathrm{M}$ phosphate-buffered saline (PBS, $\mathrm{pH}=7.4)(n=4 /$ group). The brains were removed and processed for western blot (fresh-frozen, $n=4$ /group) or immunohistochemistry (perfused-fixed, $n=4 /$ group).

\section{Restraint stress}

Single, long-duration restraint was performed as previously described (Zelena et al. 2003). The animals were placed into transparent plastic tubes (5-6 cm inner diameter) having a 4-cm-long conical head part ending with a large breathing hole. Behind the body, the rear end of the tube was loosely packed with paper towels. This method allows restraint without any pain and minimizes temperature effects. Restraint lasted for $3 \mathrm{~h}$ in the morning (08:00-11:00) and was finished by transcardial perfusion or by decapitation of the animals.

\section{In situ hybridization}

Serial coronal sections ( $12 \mu \mathrm{m}$ thick, $120 \mu \mathrm{m}$ apart) of the brains were cut using a cryostat (Leica Microsystems, Nussloch, Germany) and mounted on Superfrost Ultra Plus slides (ThermoFisher Scientific, Budapest, Hungary). The slides were stored at $-80^{\circ} \mathrm{C}$ until used.

Alternate series of sections from the caudal medulla oblongata were hybridized for either PrRP, TH or NUCB2. One series of hypothalamic sections was hybridized for PrRP receptor (PrRP-R alias GPR10). The S35-UTPlabeled (PerForm Hungaria Kft., Budapest, Hungary) riboprobes were prepared by in vitro transcription as described previously (Konczol et al. 2010; Toth et al. 2008). The specific sequences used for the hybridizations were: rat prepro-PrRP cDNA (10-240 bp of the coding sequence, accession \# AB015418), rat TH cDNA (684-1068 bp of the coding sequence, accession \# M23598) (Mezey et al. 1998), rat NUCB2 cDNA corresponding to the nesfatin-1 fragment (1-246 bp of the coding sequence, accession \# DY314804) and the rat PrRP-R cDNA (189-636 bp of the coding sequence, accession \# NM_139193) (Vas et al. 2013; Durst et al. 2019). The specificity of the cDNAs was verified by sequencing. Specificity of the probes was also controlled by performing experiments using sense probes failing to give any signals. After hybridizations, sections were apposed to BAS-MS imaging plates (Fuji Photo Film Co., LTD., Kanagawa, Japan, NJ) for 3 (PrRP, TH) or 7 (NUCB2) days. Data were read out by a Fujifilm FLA-8000 Image 
Analyzer (Fujifilm Life Science, Stamford, CT). NUCB2 as well as PrRP-R labeled sections were dipped in Kodak NTB nuclear emulsion (Carestream Health Inc., Rochester, NY) for 2 and 6 weeks, respectively, according to the manufacturer's instructions and developed using Kodak developer and fixer (Sigma). The sections were stained with Giemsa and coverslipped using DPX (Sigma).

\section{Quantitative analysis of the in situ hybridization signals}

Radioactive in situ hybridization provides a linear relationship between the signal intensity and the mRNA expression level (Chen et al. 2012). The signals in the cVLM and cDMM (i.e. NTS) were evaluated on parallel series of sections, between 14.04 and $14.70 \mathrm{~mm}$ caudal from bregma (Paxinos and Watson 2007) corresponding to the most sensitive areas for restraint stress (Dayas et al. 2001). The rostrocaudal level of the sections was carefully matched between the animals. Optical densities (mean grey values) of the signals were measured in the phosphor imager recordings in at least four sections/animal using the same settings across animals. Background values measured in parallel were subtracted. NUCB2 signal in the cVLM was weak in the screen (see the Results), therefore, it was measured in darkfield images (Olympus BX60, UPlan FL 4x/0.13) made of the autoradiographic emulsion-coated sections (SPOT Xplorer 17.4 camera, Diagnostic Instruments Inc., Sterling Heights, MI). The amount of the silver grains over the individual cells was evaluated within identical ROIs and expressed as the area (pixels) covered by grains (Wittmann et al. 2015). The signal threshold for each cell was calculated as the mean pixel value of 2-3 background samples measured in the surrounding region. Only cells with pixel values above these criteria were included in the analysis. In all cases, the sections were evaluated bilaterally with the help of the ImageJ program (Wayne Rasband NIH, Bethesda, MD), as earlier described (Vas et al. 2013; Toth et al. 2008). The average/ animal data were compared statistically. All measurements were made by an experimenter blind to the experimental settings.

\section{Hormone measurements}

Blood was collected in K-EDTA containing tubes on ice. After centrifugation, the plasma was stored at $-20{ }^{\circ} \mathrm{C}$. ACTH and corticosterone levels were measured from unextracted plasma (50 and $10 \mu$, respectively) in duplicates with a radioimmunoassay, as described earlier (Zelena et al. 2003). The intra-assay coefficient of variation was $12.5 \%$ and $17.6 \%$ for ACTH and corticosterone measurements, respectively. All samples from one experiment were measured in one assay.

\section{Microdissection of selected brain nuclei}

Fresh frozen brains were cut into $200-\mu \mathrm{m}$-thick slices in a cryostat (Leica), mounted on pre-cooled, untreated glass slides (ThermoFisher) and stored at $-80{ }^{\circ} \mathrm{C}$ until used. The regions of the cVLM and cDMM, the SON, the PVN and the AV3V were dissected out guided by the Rat Brain Atlas (Paxinos and Watson 2007), using a modified Palkovits punch technique (Palkovits 1973). Briefly, for dissection, the slides were placed back into the cryostat and kept there during the whole procedure at $-10{ }^{\circ} \mathrm{C}$. The individual nuclei were visualized using a head magnifier and removed from the sections using sterile punch needles with an inside diameter of $0.7 \mathrm{~mm}$. The punch samples were collected immediately in ice cold Eppendorf tubes containing $100 \mu \mathrm{l}$ of radioimmunoprecipitation assay buffer (RIPA, $50 \mathrm{mM}$ TrisHCl, $150 \mathrm{mM} \mathrm{NaCl}, 1 \mathrm{mM}$ EDTA, $1 \%$ Triton X-100, 0.1\% SDS, $0.25 \%$ Na-deoxycholate, $\mathrm{pH}=7.4$ ) and a cocktail of protease and phosphatase inhibitors (ThermoFisher). Samples were homogenized, lysed and then stored at $-80{ }^{\circ} \mathrm{C}$ until used for western blot.

\section{Western blot}

Samples were centrifuged to separate cell debris and nuclei $\left(20,000 \mathrm{~g}, 30 \mathrm{~min}\right.$ at $\left.4{ }^{\circ} \mathrm{C}\right)$. The protein concentrations in the supernatant were measured using the Pierce ${ }^{\mathrm{TM}} \mathrm{BCA}$ Protein Assay Kit (ThermoFisher) according to the instructions of the manufacturer. Samples containing identical brain areas were diluted to equal final protein concentrations and denatured in $2 \times$ Laemmli buffer (Bio-Rad Magyarország Kft., Budapest, Hungary). Proteins (10 $\mu \mathrm{g} / \mathrm{sample})$ were separated in a $13.5 \%$ SDS-PAGE gel with $10 \%$ stacking gel. After transferring onto PDVF membranes (Merck Millipore, Budapest, Hungary), the membrane-bound protein samples were blocked in 5\% BSA for $1 \mathrm{~h}$ and subsequently exposed to one of the following primary antibodies: anti-nesfatin-1 (1-82) (Phoenix Europe GmbH, Karlsruhe, Germany, CAT\# H-003-22, dilution 1:2000), anti-TH (Merck, CAT\# AB152, dilution 1:1000), anti-TH phosphorylated at Ser31 (Sigma, CAT\# SAB4300674, dilution 1:1000), anti-PrRP-R (ThermoFisher, CAT\# PAS 75,372, dilution 1:1000), all made in rabbit, and then to anti- $\beta$-actin (Sigma, CAT\# A1978, made in mouse, dilution 1:5000). Signals were visualized using HRP-conjugated goat anti-rabbit or mouse antibodies (Cell Signaling Technology Europe B.V., Frankfurt, Germany, dilution 1:5000) and Chemiluminescent HRP Substrate (Merck), or by fluorescently labeled goat anti-mouse IgG (AzureSpectra 700, Azure Biosystems, Dublin, CA, dilution 1:1000) and detected with the Azure c600 imaging system (Azure Biosystems). Densitometric analyses of the protein bands were performed with the help of the ImageJ 
application. The average/animal data $(n=4)$ normalized to $\beta$-actin were compared statistically.

\section{Immunohistochemistry}

Serial coronal free-floating sections $(50 \mu \mathrm{m}$-thick, $200 \mu \mathrm{m}$ apart) from the hindbrain and from the hypothalamus were immunostained for PrRP. One series of hypothalamic sections from a control Wistar rat was double immunostained for PrRP and TH. The sections were incubated in 1\% BSA containing 0.5\% TX-100 (Sigma) in PBS for $1 \mathrm{~h}$, to block non-specific binding sites in the tissues and to enhance penetration of the antibodies. The sections were then boiled using a microwave in $0.1 \mathrm{M}$ citric acid $(\mathrm{pH}=6.0)$, to perform antigen retrieval and eliminate endogenous HRP activity simultaneously (Toth and Mezey 2007). The rabbit anti-PrRP antibody (https://www.phoenixpeptide.com/products/view/ Antibodies/H-008-52, Phoenix, dilution 1:8000) was applied for 2 days at $4{ }^{\circ} \mathrm{C}$. Visualization was performed using the Vectastain-ABC-HRP Kit (Vector Laboratories, Burlingame, CA, CAT\# PK 6100) and FITC-tyramide reaction (PerForm, CAT\# NEL701A001KT). Double immunostained sections were then further incubated in mouse anti-TH (Millipore, Temecula CA, CAT\# MAB318, https://www.merckmilli pore.com, dilution 1:200) for 2 days at $4{ }^{\circ} \mathrm{C}$, and in donkey anti-mouse AlexaFluor647 (ThermoFisher, dilution 1:100) for $2 \mathrm{~h}$ at room temperature. Control immunostainings were performed by omitting the primary antibodies from the reactions and showed no signals. The sections were mounted on precleaned slides and coverslipped with Vectashield mounting medium (Vector).

\section{Evaluation of the PrRP immunostained sections}

Hindbrain sections immunostained for PrRP were evaluated between 14.04 and $14.70 \mathrm{~mm}$ caudal from the bregma level. Hypothalamic sections were analyzed between the -0.12 and $+0.24 \mathrm{~mm}$, the $0.6-1.08 \mathrm{~mm}$ and the 1.3-1.8 $\mathrm{mm}$ relative levels to bregma, and contained the $\mathrm{AV} 3 \mathrm{~V}$, the SON and the PVN, respectively (Paxinos and Watson 2007). Sections were scanned on a confocal laser scanning system using the same settings across the animals (Zeiss, LSM780, Plan-Apochromat $10 \times / 0.45 \mathrm{M} 27$, pixel size: $0.8303 \mu \mathrm{m}^{2}$, optical thickness: $25 \mu \mathrm{m}$ ). The number of PrRP-positive cells was counted in the cVLM and NTS in at least two sections per animal bilaterally, using the touch-count tool in the ImageJ application. The density of the immunoreactive fibers was determined in regions of interest (ROI: MnPO: $260 \mu \mathrm{m} \times 280 \mu \mathrm{m}$, PVN: $200 \mu \mathrm{m} \times 200 \mu \mathrm{m}$, SON: $40 \mu \mathrm{m} \times 40 \mu \mathrm{m}$ ) in two-three sections per animal, bilaterally. The area of the fibers within each ROI was determined with the help of the threshold function in the ImageJ application and divided with the area of the ROI. Measurements were made by an experimenter blind to the experimental settings. The average/animal data $(n=4)$ were compared statistically.

\section{PrRP and TH coexpression analysis}

Coexpression was measured in the above-mentioned hypothalamic areas in high magnification (Plan-Apochromat $60 \times / 1.4 \mathrm{VC}$ ) confocal images (Bio-Rad Laboratories, Hemel Hempstead, UK). For each field 16-20 single optical sections were acquired at a $z$-separation of $2 \mu \mathrm{m}$ (z-stack) from two sections/area bilaterally. Images with the most intense signals (at least 6/z-stack) were selected for analyses with the help of ImageJ application. Percentage data are expressed as means \pm SEM obtained from the four $\mathrm{z}$-stacks in each areas.

\section{Statistics}

Data analyses were performed by investigators blind to treatments. Statistical significances were calculated by employing the Sigmastat 3.5 application (Systat Software Inc., Chicago, IL). Student's $t$ test (two-tailed) was used when comparing two groups with normal distribution of the data, otherwise Mann-Whitney $U$ test was applied. Two-way ANOVA followed by Student-Newman-Keuls post hoc analysis was used for calculating statistical significance for four groups with two treatments. One-way ANOVA with repeated measures was used to analyze fluid and food intake values across the 6 days of HS or NS. Data were assessed for normality and equal variances before running ANOVA analyses. Results are expressed as means \pm SEM values. Pearson method was used to calculate correlations. Differences between groups were considered statistically significant when $p<0.05$.

\section{Results}

\section{Body parameters, food and water intake}

Lower bodyweight $(p<0.05)$ and higher plasma osmolalities $(p<0.001)$ were measured in DI animals compared to the age-matched WT peers. Despite the chronic hypernatremia, the relative adrenal and thymus weights were normal. DI rats consumed less food than WT rats $(p<0.01)$, but since they consumed according to their bodyweight, no alteration in the relative daily food intake was seen. The excessive absolute and relative daily water intake $(p<0.001$ for both parameters) however, confirmed the diagnosis of diabetes insipidus (Table 1).

In Wistar rats, high salt intake for 6 days resulted in dramatic weight loss as opposed to weight gain observed in controls $(p<0.001)$. The plasma osmolality was elevated compared to non-challenged (NS) mates $(p<0.001)$, 
Table 1 Body parameters, daily food and water intakes of homozygous (+/+ and -/-) Brattleboro rats

\begin{tabular}{lll}
\hline & WT & DI \\
\hline Body weight $(\mathrm{g})$ & $408 \pm 93$ & $56^{*} \pm 15$ \\
Plasma osmolality (mOsm/L) & $305 \pm 43$ & $35^{* * *} \pm 2$ \\
Relative adrenal weight $(\mathrm{g} / \mathrm{bwkg})$ & $97 \pm 59$ & $5 \pm 9$ \\
Relative thymus weight $(\mathrm{g} / \mathrm{bwkg})$ & $923 \pm 82$ & $815 \pm 78$ \\
Food intake $(\mathrm{g})$ & $24 \pm 1$ & $21^{* *} \pm 1$ \\
Relative food intake $(\mathrm{g} / \mathrm{bwkg})$ & $66 \pm 3$ & $63 \pm 3$ \\
Water intake $(\mathrm{g})$ & $31 \pm 1$ & $147^{* * *} \pm 6$ \\
Relative water intake $(\mathrm{g} / \mathrm{bwkg})$ & $76 \pm 3$ & $415^{* * *} \pm 16$ \\
$n$ & 7 & 7 \\
\hline
\end{tabular}

Food and water consumptions were measured for 5 consecutive days

Means \pm SEM, Student's $t$ tests, $p^{*}<0.05, \quad p^{* *}<0.01 \quad$ and $p^{* * *}<0.001$ vs. WT

$D I$ vasopressin-deficient genotype with diabetes insipidus, $W T$ wildtype animals of the Brattleboro strain

Table 2 Effect of $2 \% \mathrm{NaCl}$ solution (high salt; HS) intake for 6 days on body parameters of Wistar rats

\begin{tabular}{lll}
\hline & NS & HS \\
\hline Bodyweight change (g) & $49 \pm 2$ & $-46^{* * *} \pm 5$ \\
Plasma osmolality (mOsm/L) & $304 \pm 1$ & $363^{* * *} \pm 7$ \\
Relative adrenal weight (g/bwkg) & $166 \pm 8$ & $219^{*} \pm 17$ \\
Relative thymus weight (g/bwkg) & $2349 \pm 139$ & $944^{* * *} \pm 102$ \\
$n$ & 8 & 8 \\
\hline
\end{tabular}

Control subjects received tap water (normal salt; NS). Means \pm SEM, Student's $t$ tests, $p^{*}<0.05$ and $p^{* * *}<0.001$ vs. NS
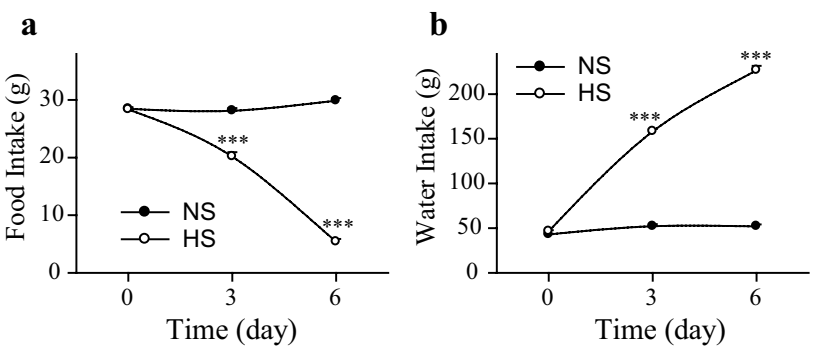

Fig. 1 Food (a) and fluid (b) consumptions of high salt loaded and normal Wistar rats. High salt solution intake evoked dramatic reduction and elevation in food and fluid consumption, respectively. Means \pm SEM, Student's $t$ tests, $p^{* * *}<0.001$ vs. the same day values of non-salt loaded control rats, $n=16$. $H S 2 \% \mathrm{NaCl}$ intake for 6 days, $N S$ normal salt solution (tap water) drinking controls

or even DI rats $(p<0.01)$. HS rats suffered from chronic stress; they developed adrenal hypertrophy $(p<0.05)$ and extensive thymus involution $(p<0.001)$ during the a

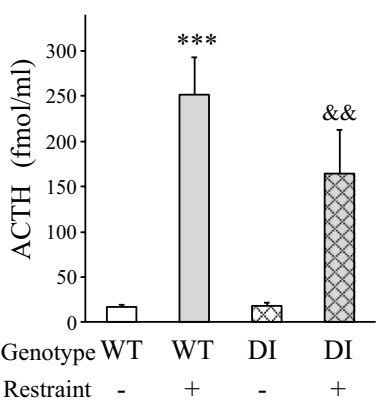

b

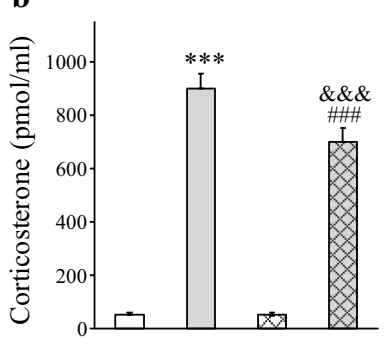

Genotype WT WT DI DI

Restraint - + - + c

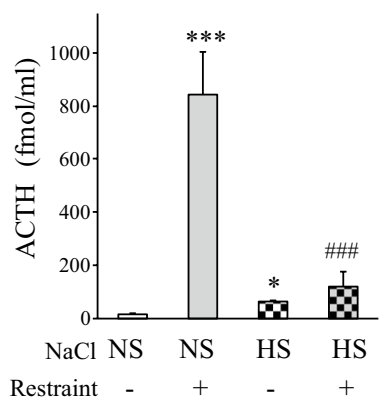

d

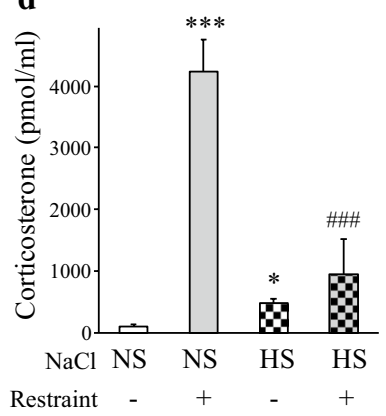

Fig. 2 Plasma adrenocorticotropic hormone and corticosterone concentrations in chronic hypernatremia and $1 \mathrm{~h}$ after acute restraint stress. ACTH (a) and corticosterone (b) levels in homozygous WT and DI Brattleboro rats. The basal hormone levels were similar between the WT and DI genotypes. The acute restraint (R) evoked large ACTH and corticosterone elevations in both genotypes, although the corticosterone response in the DI-R group was slightly reduced compared to the WT-R group. ACTH (c) and corticosterone (d) levels in the HS model. Chronic hypernatremia elicited by HS intake resulted in mild, but significant elevations in basal hormone levels. The acute restraint evoked large ACTH and corticosterone responses in the NS-R group. Hormonal responses were greatly inhibited in the HS-R group. Means \pm SEM, Student's $t$ test, $p^{*} \leq 0.001$ HS vs. NS control group, Two-way ANOVA, significance indicate the results of Student-Newman-Keuls post hoc tests, $p^{* * *} \leq 0.001$ vs. the WT or NS control groups, $p^{\# \# \#} \leq 0.001$ vs. the WT-R or NS-R group, $p^{\& \& \&} \leq 0.001$ and $p^{\& \&} \leq 0.01$ vs. the DI control group, DI model: $n=7$; HS model: $n=7-8$. ACTH adrenocorticotropic hormone, $D I$ vasopressin-deficient genotype with diabetes insipidus, $W T$ homozygous wild-type animals of the Brattleboro strain

treatment (Table 2). Food intake decreased $(p<0.001)$ (Fig. 1a), while fluid intake increased $(p<0.001)$ (Fig. 1b) gradually during HS intake.

\section{Plasma ACTH and corticosterone concentrations}

The basal ACTH and corticosterone levels were normal in DI rats suggesting the HPA axis was adapted to the congenital hypernatremia (Fig. 2a, b). The acute stress (restraint) evoked large ACTH (WT vs. WT-R: $p<0.001$, DI vs DI-R: $p<0.01$ ) and corticosterone (WT vs. WT-R and DI vs DI-R: $p<0.001)$ release. The corticosterone response was slightly 
Fig. 3 Tyrosine hydroxylase and prolactin-releasing peptide mRNA levels in chronic hypernatremia and $3 \mathrm{~h}$ after acute restraint stress in the caudal ventrolateral medulla. a Location of the cVLM (left) and illustrative autoradiographic pictures (right). The red shaded regions in the drawing (Paxinos and Watson 2007) label the cVLM. The images display the in situ hybridization signals (dark spots) and were captured by storage phosphor screens. Distance from the bregma is indicated in millimeters. Scale: $4 \mathrm{~mm}$. b, c TH mRNA. In Brattleboro rats, restraint evoked large increase, whereas the genotype had no effect (b). HS or restraint applied separately evoked TH mRNA level elevations in Wistar rats. Prior HS blunted the TH response for restraint (c). d-g Associations between the TH mRNA and ACTH or corticosterone levels. Both ACTH (d) and corticosterone (f) values showed strong relationships with TH mRNA levels in the DI model. There were no associations between these data (e and $\mathbf{g}$, respectively) in the HS intake model. $\mathbf{h}$, i PrRP mRNA. Both the DI genotype and restraint increased PrRP mRNA levels in Brattleboro rats, resulting in the largest reaction in the DI-R group (h). HS or restraint applied separately evoked PrRP mRNA level elevations in Wistar rats. Prior HS blunted the response for restraint (i). Bar graphs: means \pm SEM, Two-way ANOVA, significance indicate the results of Student-Newman-Keuls post hoc tests, $p^{* * *}<0.001, p^{* *}<0.01$, or $p^{*}<0.05$ vs. WT or NS control groups, $p^{\# \#}<0.01$ vs. WT-R animals, $p^{\& \& \&}<0.001$ and $p^{\&}<0.05$ vs. DI control rats, DI model: $n=7$; HS model: $n=8$. Correlation graphs: solid and dashed lines show linear regressions and $95 \%$ confidence intervals, respectively, see Pearson correlation coefficients $(r)$ in the graphs, $p^{* * *}<0.001, p^{* *}<0.01$, DI model: $n=28$; HS model: $n=31$. PrRP prolactin-releasing peptide, $T H$ tyrosine hydroxylase, $c V L M$ caudal ventrolateral medulla

subnormal in DI-R rats (WT-R vs. DI-R: $p=0.001$ ) (Fig. 2a, b).

HS intake resulted in elevated basal ACTH and corticosterone levels (Student's $t$ tests, $p \leq 0.001$ for both parameters) (Fig. 2c, d). The acute restraint evoked large ACTH and corticosterone release (NS vs. NS-R: $p<0.001$ for both hormones), but the responsiveness of the HPA axis was greatly inhibited in the HS-R group (NS-R vs. HS-R: $p<0.001$ for both hormones, HS vs. HS-R: no significant differences) (Fig. 2c, d).

Very high correlations were found between the ACTH and corticosterone values in both models $\left(R_{\mathrm{DI}}\right.$ model $=0.827$, $n=28$; and $R_{\mathrm{HS}}$ model $\left.=0.907, n=31, p<0.00001\right)$, indicating that the sensitivity of adrenal corticosterone secretion to plasma ACTH levels was maintained.

\section{TH, PrRP and NUCB2 mRNA levels in the CVLM}

In the cVLM (Fig. 3a), the basal amounts of TH mRNA were similar in the WT and DI rats (Fig. 3b), but differed between the NS and HS animals (NS vs. HS: $p<0.01$ ) (Fig. 3c). The acute restraint evoked large increase in TH mRNA levels in the wild-type and DI Brattleboro rats (WT vs. WT-R and DI vs. DI-R: $p<0.001$ ) (Fig. 3b), and in the normal Wistar rats (NS vs. NS-R: $p<0.05$ ) (Fig. 3c). HS animals with elevated TH mRNA levels however, failed to react to restraint with TH mRNA increase (Fig. 3c). Therefore, TH mRNA levels correlated well with ACTH $(p<0.01)$ and corticosterone $\mathbf{a}$

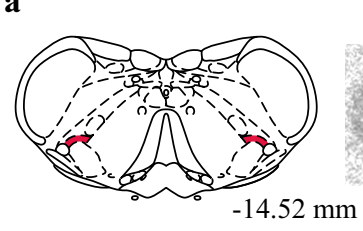

b

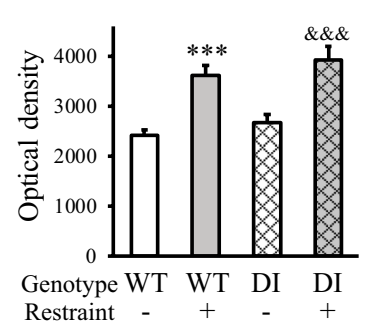

d

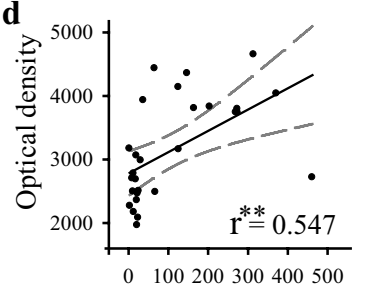

ACTH (fmol/ml)

f

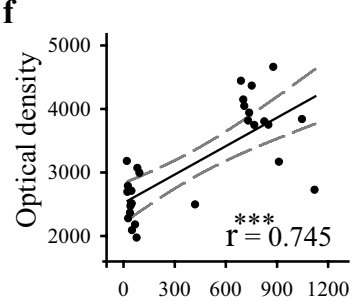

Corticosterone $(\mathrm{pmol} / \mathrm{ml})$

h

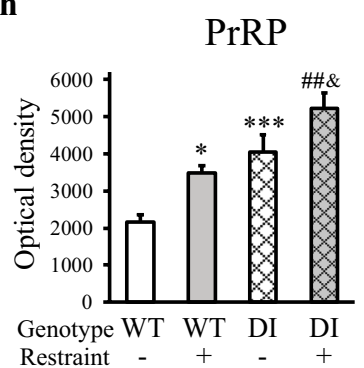

$\mathrm{TH}$

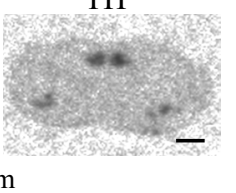

c

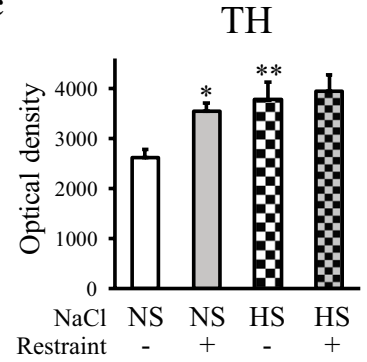

e

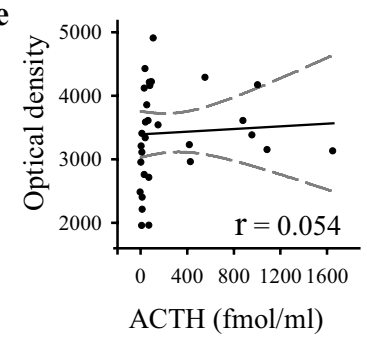

g

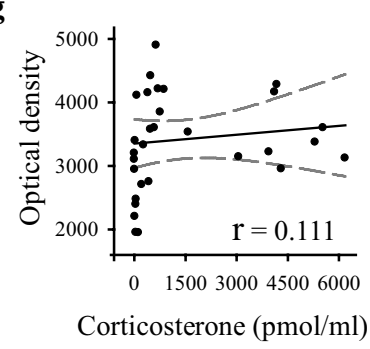

i

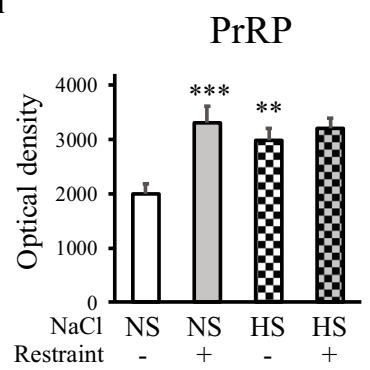

$(p<0.001)$ levels in the DI (Fig. 3d, f), but not in the HS intake model (Fig. 3e, g).

PrRP mRNA quantity was heightened by both DI (WT vs. DI: $p<0.001$ ) and restraint (WT vs WT-R: $p<0.05$ ), resulting in the highest mean value in the DI-R group (WT-R vs. DI.-R: $p<0.01$, DI vs DI-R: $p<0.05$ ) (Fig. 3h). PrRP mRNA changes in the HS model were similar to that of $\mathrm{TH}$ mRNA (NS vs. HS: $p<0.01$ and NS vs. NS-R: $p<0.001$ ). The PrRP mRNA response to the acute restraint was entirely impeded in the HS-R animals (Fig. 3i). 

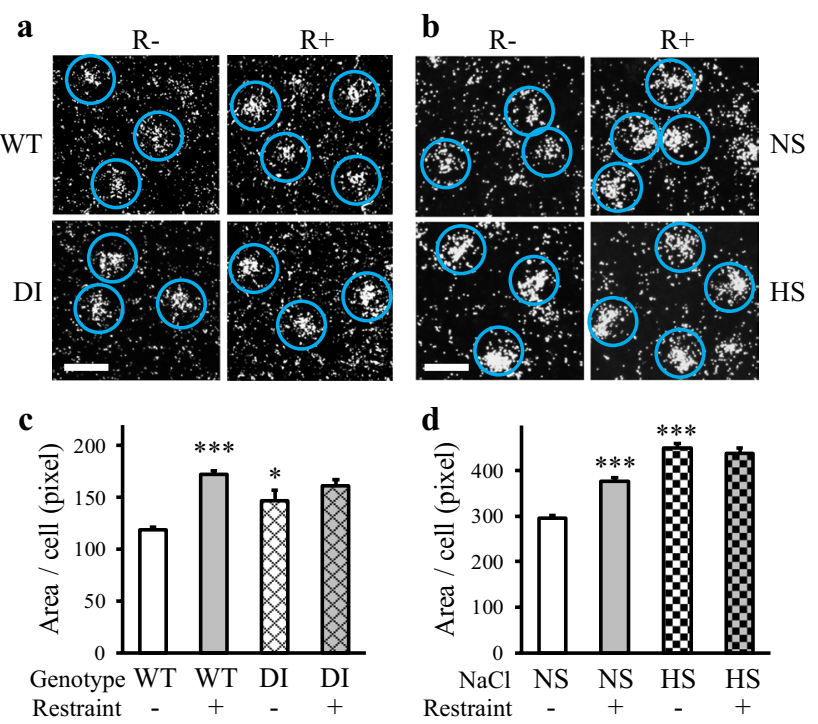

Fig. 4 NUCB2 mRNA levels in chronic hypernatremia and $3 \mathrm{~h}$ after acute restraint stress in the cVLM. a, b Illustrative darkfield microphotographs of the autoradiographic emulsion-coated sections displaying NUCB2 mRNA expressing cells encircled by blue ROIs. The in situ hybridization signals are seen as clusters of silver grains (white dots) over the cells. Scales: $40 \mu \mathrm{m} \mathrm{c}$, d Chronic hypernatremia and restraint elevated NUCB2 mRNA levels in both models, when applied separately. No reactions were observed in the double challenged rats. Means \pm SEM, two-way ANOVA, significance indicate the results of Student-Newman-Keuls post hoc tests, $p^{* * *}<0.001$, $p^{*}<0.05$ vs. WT or NS control rats, DI model: $n=4-5$; HS model: $n=8$

NUCB2 mRNA expressing cells were clearly visible in the emulsion-coated sections (Fig. 4a, b). The signal intensities were higher in hypernatremic animals (WT vs. DI: $p<0.05$, NS vs. HS: $p<0.001$ ), and in the restraint stressed groups (WT vs. WT-R and NS vs. NS-R: $p<0.001)$ compared to normal controls. Prior chronic osmotic stress inhibited the NUCB2 responses to restraint in both models (Fig. 4c, d).

\section{TH, PrRP and NUCB2 mRNA levels in the CDMM}

In the cDMM (Fig. 5a), TH, PrRP and NUCB2 mRNA levels were unaffected by acute restraint in both models (Fig. 5b-g). The amounts of TH mRNA were also normal in the hyperosmotic DI and HS rats (Fig. 5b, c).

PrRP mRNA values were increased in the DI rats (WT vs. DI and WT-R vs. DI-R: $p<0.001$ ), (Fig. $5 \mathrm{~d}$ ), but they were reduced by HS intake (NS vs. HS: $p<0.01$, NS-R vs. HS-R: $p<0.001$ ) (Fig. 5e).

NUCB2 mRNA levels have changed similarly to that of PrRP mRNA in the Brattleboro rats and they were elevated by hyperosmolality (WT vs. DI: $p=0.01$, WT-R vs. DI-R: $p<0.05)$ (Fig. 5f). HS intake also increased the a

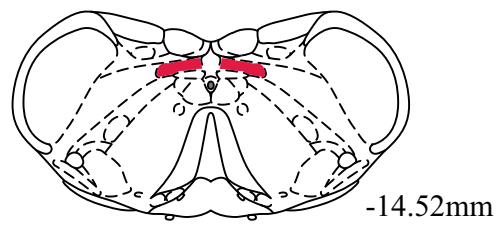

TH

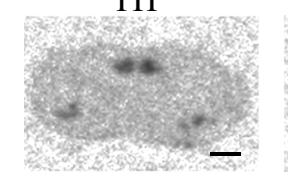

PrRP

TH

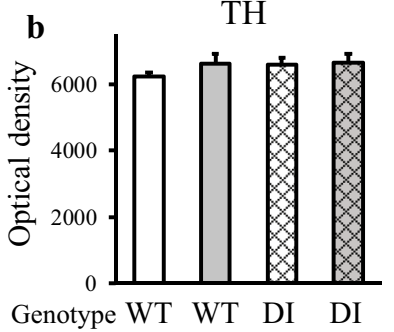

Genotype WT WT DI DI Restraint

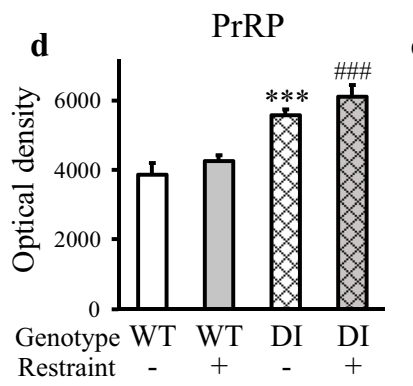

c

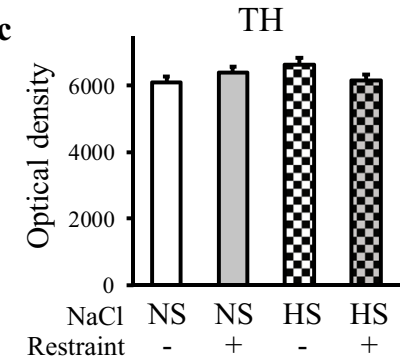

e
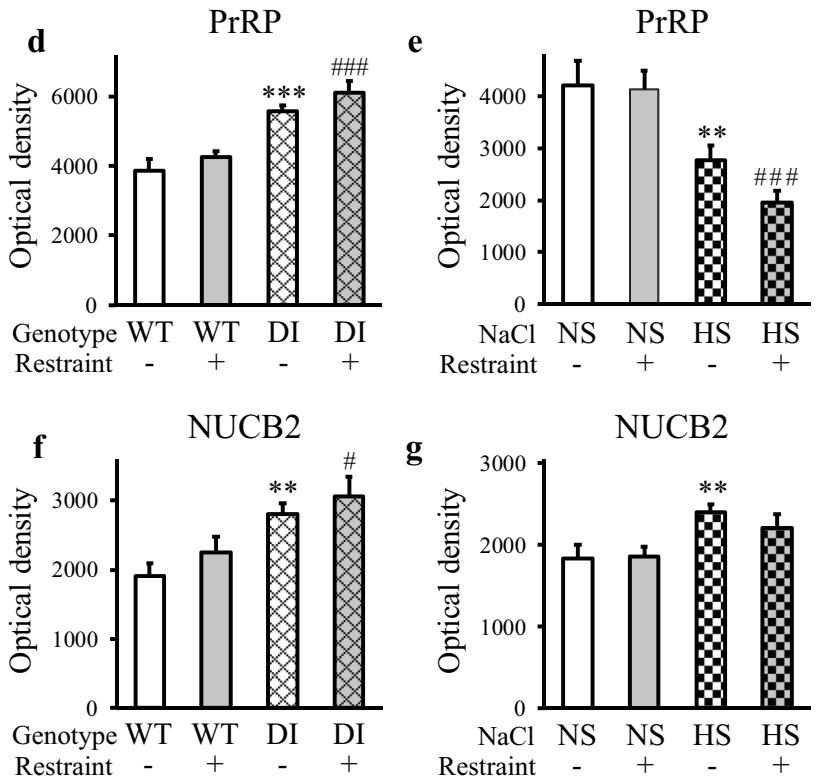

Fig. $5 \mathrm{TH}$, PrRP and NUCB2 mRNA levels in chronic hypernatremia and $3 \mathrm{~h}$ after acute restraint stress in the caudal dorsomedial medulla. a Location of the measured area within the cDMM (top) and illustrative autoradiographic pictures (bottom). The red shaded regions in the drawing (Paxinos and Watson 2007) label the measured area (nucleus of the solitary tract). The images display the in situ hybridization signals (dark spots), and were captured by storage phosphor screens. Distance from the bregma is indicated in mm. Scale: $4 \mathrm{~mm}$. b, c TH mRNA. There were no alterations in either of the hypernatremia models; DI (b), HS intake (c). d, e PrRP mRNA. Increased levels were measured in the AVP deficient Brattleboro rats, independently of restraint (d). Depressed amounts of PrRP mRNA were detected in Wistar rats challenged by HS intake (e). Restraint had no effect in either of the models. f, g NUCB2 mRNA. Chronic hypernatremia elevated NUCB2 mRNA levels in both models. Restraint had no effect in either of the models. Means \pm SEM, Two-way ANOVA, significance indicate the results of Student-Newman-Keuls post hoc tests, $p^{* * *}<0.001$ and $p^{* *} \leq 0.01$ vs. WT or NS control rats, $p^{\# \# \#}<0.001$ and $p^{\#}<0.05$ vs. WT-R or NS-R animals, DI model: $n=7$ (b, d), $n=4-5$ (f); HS model: $n=8$. $c D M M$ : caudal dorsomedial medulla 
levels of NUCB2 mRNA (WT vs. HS: $p<0.01$, NS-R vs. HS-R: $p=0.085$ ) (Fig. 5g).

\section{Chronic high salt intake evoked changes in protein expressions in the medulla and the hypothalamus}

To better understand the molecular mechanisms of adaptation to chronic hypernatremia, we performed further investigations in the HS model. In harmony with the mRNA results, both TH $(p<0.05)$ and NUCB2 $(p<0.05)(43 \mathrm{kDa}$ product) protein levels (measured by Western blot) were heightened by chronic HS intake in the cVLM (Fig. 6a). No alterations were measured in the amounts of these proteins in the cDMM (Fig. 6a). PrRP isoforms (PrRP31: $3.6 \mathrm{KDa}$, PrRP20: $2.6 \mathrm{KDa}$ ) were too small for western blot analysis. Therefore, the number of the PrRP-immunopositive cells was determined to evaluate expressional changes. The number of the PrRP-immunopositive cells was higher in the HS compared to NS group $(p<0.05)$ in the cVLM, in agreement with the mRNA measurements. However, in the cDMM, where we found reduced PrRP mRNA levels in the HS group, the number of the PrRP-immunopositive cells was maintained (Table 3 ).

PrRP and TH innervations were analyzed in the main osmoregulatory centers: the AV3V, PVN and SON. The PrRP fiber network was the richest in the PVN. More than two-thirds of the analyzed varicosities contained both $\mathrm{TH}$ and PrRP immunoreactivity in the AV3V and the PVN, and almost all were double labeled in the SON in control rats (Fig. 6b, c). Thus, the majority of the PrRP-positive fibers originated from the A1 or A2 cell groups. HS intake enhanced the density of the PrRP-positive fibers in all of the investigated regions $(p<0.05)$, (Table 3, Fig. 6d, e). Within the PVN, this was more obvious in the medial parvocellular region and less in the magnocellular parts of the nucleus, where the PrRP fiber network was poor (Fig. 6e). Several neurons expressed PrRP-R in the AV3V (mainly in the $\mathrm{MnPO}$ and in the anteroventral periventricular nucleus) and the medial parvocellular PVN. Neurons in the magnocellular PVN and SON failed to express PrRP-R (Fig. 6f). Chronic hypernatremia downregulated the amount of the PrRP-Rs (measured by Western blot) in the PVN $(p<0.05)$. The decrease in the AV3V did not reach the level of significance (Fig. 6g). Parallel with the increased PrRP innervation, TH phosphorylation at Ser31 (TH-Ser31) was upregulated in all of the HS samples (AV3V, SON: $p<0.05$, PVN: $p<0.001$ ) indicating a stimulated catecholamine release (Fig. $6 \mathrm{~g}$ ).

\section{Discussion}

Chronic hypernatremia triggers central reactions affecting the neuroendocrine, autonomous and behavioral circuits. NE and PrRP containing medullary axons target critical hypothalamic centers organizing these reactions and probably exert an enhanced signaling during chronic hypervolemic hypernatremia. Cooperation of NE and PrRP under this condition may represent a basis for the ongoing adaptation mechanisms. Contribution of nesfatin acting by autocrine/ paracrine manner within the $\mathrm{cVLM}$ and $\mathrm{CDMM}$ is also suggested.

High salt solution intake for 6 days resulted in the development of typical, somatic signs of chronic stress due to the chronic, mild elevation of the resting plasma corticosterone level in adult rats. In contrast, genetically AVP deficient adult DI rats exhibited no somatic signs of chronic stress and normal basal plasma ACTH and corticosterone concentrations. The difference between the two models may explain the above findings. DI causes euvolemic hypernatremia, as an outcome of water loss through the kidneys, without high blood pressure (Sun 2006). In contrast, sodium overconsumption causes hypervolemic hypernatremia, elevated plasma AVP concentration and blood pressure (Choe et al. 2015). The plasma osmolality in the DI group was significantly lower than in the HS group. The mean corrected food intake of DI rats was normal. HS intake, however, caused dehydration-induced anorexia (Boyle et al. 2012). During the embryonic development, several alterations take place in the expression of different genes and neuronal pathways in DI rats to compensate for the lack of AVP (Scholer and Sladek 1981; Bundzikova et al. 2008; Pouzet et al. 2001; Yang and Coote 2007). Plasticity in response to challenges in adulthood is much more limited. All in all, HS intake represented a higher degree of homeostatic threat for the cardiovascular and osmotic control as well as the regulation of the energy balance. This definitely produced a higher level of stress in animals challenged by HS intake compared to DI rats.

Severe functional impairment of the HPA axis was displayed only when hypernatremia evoked serious chronic stress: the ACTH and corticosterone responses to acute restraint were absent in HS-R animals, while they were almost intact in the DI-R group. These hormonal responses to acute restraint greatly depend on the ascending medullary NE transmission towards the PVN (Gaillet et al. 1991; Pacak et al. 1995; Flak et al. 2014). Indeed, the acute restraint upregulated the expression of $\mathrm{TH}$ in the $\mathrm{A} 1$ cell group in the non-hypernatremic rats in both models (WT-R, NS-R). It seemed, however, that the type of hypernatremia affected the basal level of TH in the A1 cell group differentially (normal in DI and high in HS rats), and the level of TH determined 
$\mathbf{a}$

$\mathrm{TH}$
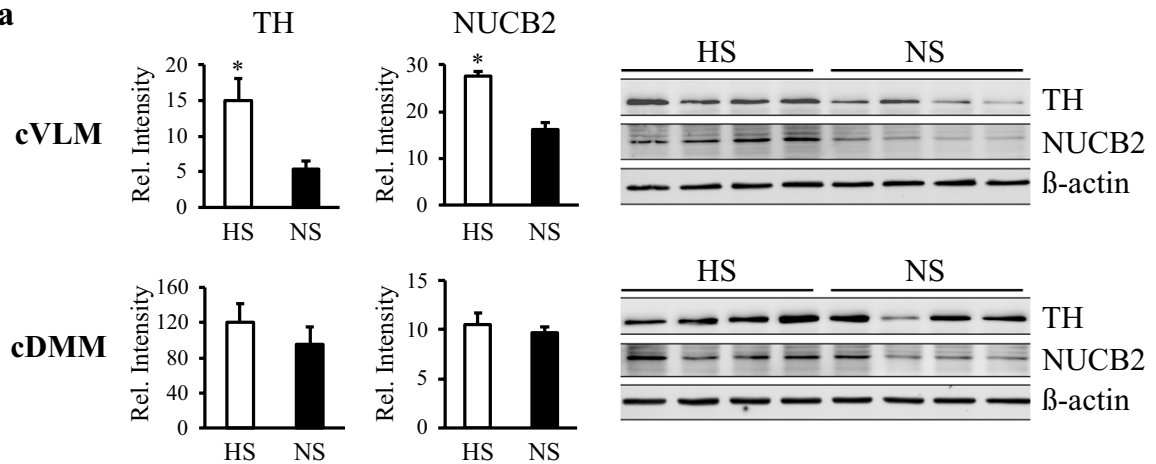

b

c

d

e

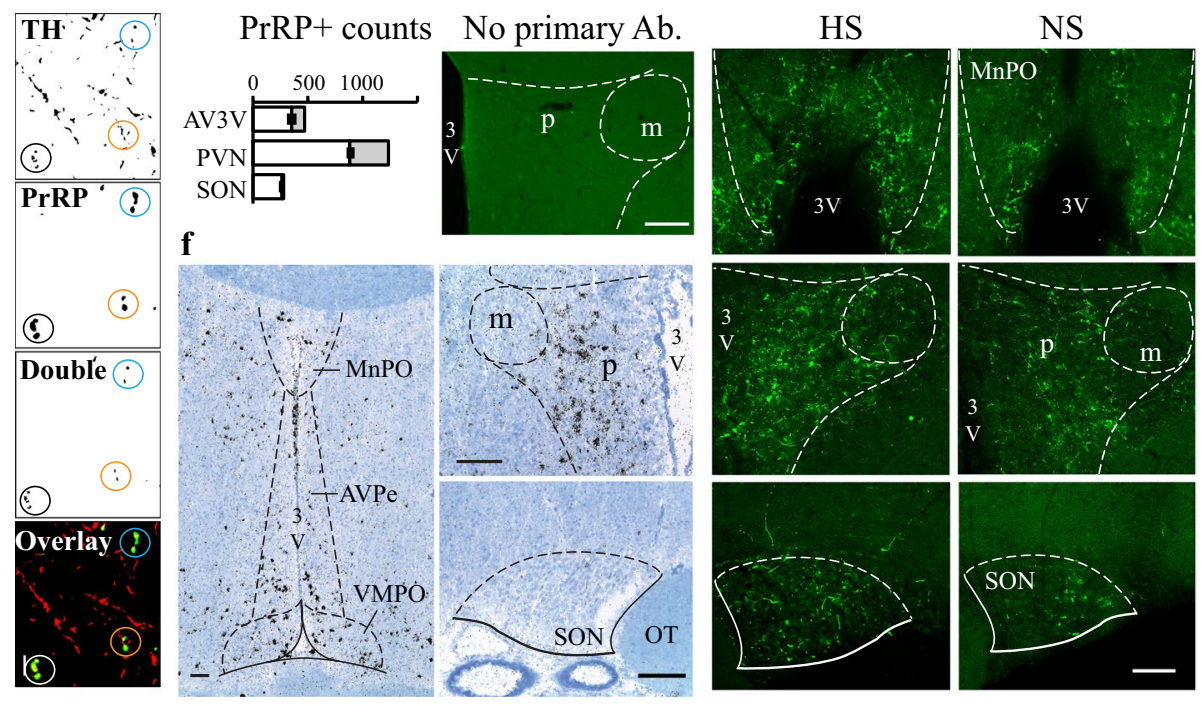

g

pTH-Ser31 PrRP-R
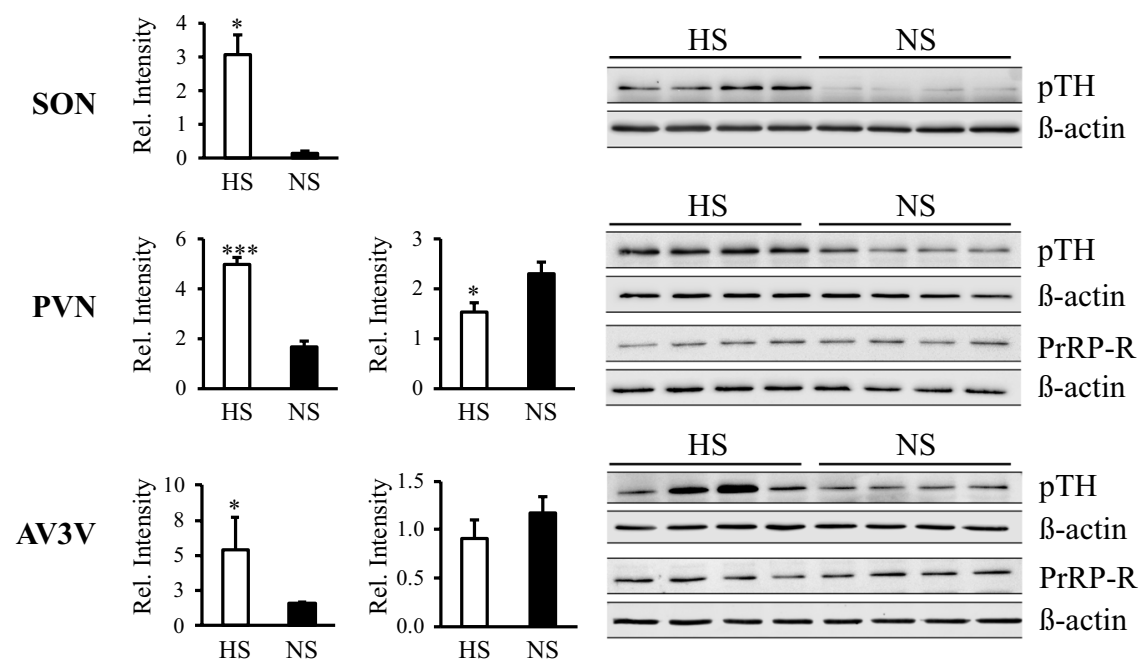

the responsiveness of the HPA axis for the acute restraint (normal in DI-R and blunted in HS-R rats). The correlation data between the $\mathrm{TH}$ and $\mathrm{ACTH} /$ corticosterone measurements confirmed this idea. Thus, a ceiling effect in the TH (the rate limiting enzyme for NE synthesis) expression may have contributed to the impaired HPA axis responsiveness.

The exhaustion of TH capacity in the A1 cell group in chronic HS intake occurs probably for complex reasons. Chronic HS intake challenges strongly the osmotic and 
4Fig. 6 Chronic high salt intake induced changes in protein expressions. a Western blots and quantification of TH and NUCB2 signals in the cVLM and cDMM. Intensity values were normalized to $\beta$-actin. TH and NUCB2 protein levels were heightened in the cVLM, but not in the cDMM in response to HS intake. b Coexpression analysis of TH- and PrRP- immunoreactive profiles in normal Wistar rats. Illustrative, binary, confocal images (single optical layer) and the color-coded overlay picture (red: TH, green: PrRP, yellow: coexpression) of the same field within the SON. The identical circles feature identical elements. Double-labeled elements were calculated by the ImageJ program. Scale: $10 \mu \mathrm{m}$. c Quantitative results of the coexpression analysis. The number of PrRP-positive profiles were the highest in the PVN. Most of the counted profiles were double-labeled for TH and PrRP (white columns). The amount of the single PrRP-positive profiles were less than $30 \%$ in the AV3V and the PVN, and less than $10 \%$ in the SON (grey columns). d, e HS intake elicited changes in PrRP immunoreactivity. Control immunostaining for PrRP in the PVN (d). No signal is seen by omitting the primary antibody from the reaction. HS intake increased the density of PrRP-positive fibers in all investigated regions (e): the AV3V (MnPO, top), PVN (middle) and SON (bottom). Note, that PrRP fibers expand both in the parvoand the magnocellular parts of the PVN during HS intake. Scale: $100 \mu \mathrm{m}$. f Pattern of the PrRP-receptor mRNA expression in the investigated hypothalamic areas. In situ hybridization signals (black silver grain clusters) in the AV3V region (left), the PVN (top right) and the SON (bottom right). Positive cells are present in the AV3V and the parvocellular PVN. Note, signals avoid the magnocellular PVN and the SON. The sections were counterstained with Giemsa. Scales: $100 \mu \mathrm{m}$. g Western blots and quantification of pTH-Ser31 and PrRP-receptor peptide levels in the hypothalamus. Intensity values were normalized to $\beta$-actin. The amounts of pTH-Ser31 increased in all measured regions in HS rats. PrRP-receptor level decreased in the PVN in response to HS. Means \pm SEM, Student's $t$ test, $p^{* * *}<0.001$, $p^{*}<0.05$ vs. NS group, $n=4$. $A b$ antibody, $A V 3 V$ anteroventral third ventricular area, $A V P e$ anteroventral preoptic nucleus, $M n P O$ median preoptic nucleus, $O T$ optic tract, $\operatorname{PrRP}-\mathrm{R}$ PrRP-receptor, $p T H-S e r 31$ phosphorylated TH at Ser31, $P V N$ hypothalamic paraventricular nucleus, $m$ magnocellular and $p$ parvocellular parts of the PVN, SON supraoptic nucleus, $V M P O$ ventromedial preoptic nucleus, $3 \mathrm{~V}$ third ventricle

cardiovascular regulations and NE of A1 origin is crucial for these functions (Day 1989; Fernandez-Galaz et al. 1994; Tanaka et al. 1997; Pedrino et al. 2008). It probably also plays an important role in the chronic activation of the HPA axis during hypernatremia, since the medullary catecholamine cell groups mediate HPA axis responses for stimuli that signal homeostatic perturbations (Ulrich-Lai and Herman 2009; Gaillet et al. 1991; Pacak et al. 1995; Ritter et al. 2003; Bienkowski and Rinaman 2008; Khan et al. 2011).

According to our data, PrRP and nesfatin may assist within certain limits when the need for NE is high. Moreover, the regulation of the TH, PrRP and nesfatin genes is coordinated. Both were upregulated by restraint and by chronic hypernatremia in the cVLM in both models. The acute restraint evoked PrRP response was in association with the TH capacity and the overload of the stress axis. Thus, it was maintained in the DI, but not the HS loaded rats. The nesfatin response to restraint was blunted by prior chronic hypernatremia in both models. Coordinated regulation of the genes coding TH, PrRP and nesfatin within the same cell can happen in several ways. Glucocorticoids exert central feedback in stress by regulating gene expression. Glucocorticoid signaling is altered in the A1 neurons by chronic stress (Kitayama et al. 1989), which may affect the expression of $\mathrm{TH}, \mathrm{PrRP}$ and nesfatin. The expression of these genes may also be affected by neural inputs modulating the excitability of cells. Such inputs may arrive primarily from the cDMM, forwarding essential information from the peripheral baroand osmoreceptors (Chan et al. 1995), and from the hypothalamus, exerting a descending control (Toth et al. 1999; Bourque 2008). Moreover, local regulatory short loops may be important in neuromodulation. Nesfatin is a good candidate acting by an autocrine/paracrine way (Foo et al. 2008). In vitro effects of nesfatin on the excitability of cDMM and PVN neurons have already been demonstrated (Price et al. 2008; Mimee et al. 2012).

During habituation to chronic salt loading, restraint and inflammatory stress upregulation of AVP was observed in the CRH neurons of the parvocellular PVN (Harbuz et al. 1992; Ma and Lightman 1998; Amaya et al. 2001; Toth et al. 2008). AVP may contribute to ACTH (and corticosterone) secretion acting on the anterior lobe of the pituitary via V1b receptors in synergism with CRH (Antoni 1993). Actually, the role of parvocellular AVP was emphasized in the development of the blunted ACTH response to acute stress (restraint) in Sprague-Dawley rats with chronic osmotic stimulation (water deprivation) (Grinevich et al. 2001). However, the ACTH response was just marginally impaired in DI rats with no AVP, compared to the HS intake rats. This controversy may also be due to the limitation of the knock-out model. Nevertheless, upregulation of PrRP in the NE neurons takes place during adaptation to chronic restraint in the medulla (Toth et al. 2008). By demonstrating the upregulation of the coexpressed neurotransmitters in the cVLM in chronic hypernatremia, we showed that this phenomenon is part of a general mechanism in habituation to chronic stressful stimuli.

The adaptation of the "healthy organism" to chronic hypernatremia has further been investigated in the HS model with aggressive alterations in the measured parameters and lacking the compensatory mechanisms that had been developed in the AVP-deficient rats throughout the ontogenesis.

TH, PrRP and NUCB2 protein levels were all elevated in the cVLM in the HS group compared to the NS group. This was in harmony with the mRNA data pointing to a balanced reaction to an increased demand. In the cDMM, discrepancies were found between the mRNA and protein data, pointing to an increased demand for PrRP and nesfatin that disturbed the dynamics between the synthesis and transport/ release (Sterrenburg et al. 2011).

The increased NE and PrRP turnover during high salt loading was confirmed by the examination of the 
Table 3 Prolactin-releasing peptide immunoreactivity in the different brain areas after high salt intake

\begin{tabular}{|c|c|c|c|c|c|c|}
\hline & \multicolumn{2}{|c|}{ Cell number/section } & \multicolumn{3}{|c|}{ Fiber density $\left(\mu \mathrm{m}^{2} / 100 \mu \mathrm{m}^{2}\right)$} & \multirow[t]{2}{*}{$n$} \\
\hline & cVLM & $\mathrm{cDMM}$ & AV3V & SON & PVN & \\
\hline NS & $6.3 \pm 0.8$ & $52.3 \pm 3.7$ & $1.2 \pm 0.2$ & $1.0 \pm 0.1$ & $4.2 \pm 0.2$ & 4 \\
\hline HS & $10.8 * \pm 1.4$ & $52.5 \pm 5.4$ & $3.0^{*} \pm 0.2$ & $1.4^{*} \pm 0.1$ & $10.2 * \pm 1.6$ & 4 \\
\hline
\end{tabular}

$A V 3 V$ periventricular anteroventral third ventricle region, $c D M M$ caudal dorsomedial, $c V L M$ caudal ventrolateral medulla oblongata, $P V N$ hypothalamic paraventricular nucleus, $S O N$ supraoptic nucleus. Means \pm SEM, Student's $t$ tests, $p^{*}<0.05$ vs. NS controls hypothalamic terminal fields. The elevated pTH-Ser31 levels pointed to an ongoing NE release (Dunkley et al. 2004; Haycock 1993; Daubner et al. 2011; Ong et al. 2012) in the SON, PVN and the AV3V in HS rats. Undoubtedly, since NE innervation of these areas arises almost exclusively from the A1 and A2 cell groups (AV3V: 100\%, PVN: $94 \%$, SON: $89 \%$ ), NE has been released primarily from the axons of the A1 and A2 cells (Sawchenko and Swanson 1981). The A1 and A2 neurons are practically identical to PrRP neurons (Chen et al. 1999), and a very high percentage of the PrRP-positive fibers was of A1 or $\mathrm{A} 2$ origin in the AV3V, PVN and SON. Together with the heightened density of PrRP-positive fibers found in the investigated hypothalamic regions in the HS group, these results provide convincing evidence that the sustained NE release is linked with PrRP corelease.

Regarding the known cooperation between NE and PrRP in the AVP and ACTH release (Maruyama et al. 2001; Uchida et al. 2010), as well as in habituation to chronic stress (Toth et al. 2008), we assume that PrRP acts synergistically with NE in the different responses to chronic hypernatremia. Coordinated or independent PrRP release, however, from the non-NE PrRP cells located in the dorsomedial nucleus cannot be excluded.

Several central behavioral, autonomic and hormonal reactions are triggered by the increased plasma sodium level. These include the generation of thirst, reducing sodium appetite, increasing renal sodium excretion and water retention, elevation of blood pressure and parallel activation of renal sympatho-inhibition (Bourque 2008; Dos Santos Moreira et al. 2017). Noradrenergic inputs to the SON, PVN and the AV3V from the A1 and A2 cell groups are essential to trigger these reactions (Fernandez-Galaz et al. 1994; Pedrino et al. 2005, 2008, 2012; Dos Santos Moreira et al. 2017). Based on our results, the central role of PrRP in all these functions is therefore emerging.

In the parvocellular PVN, not only the density of the PrRP fibers was enhanced, but the receptors were also downregulated, further confirming the augmentation of PrRP release in HS rats. This highlights the putative role of PrRP in the control of the dehydration-induced anorexia (in addition to the already discussed regulation of the HPA axis). Both food intake and bodyweight of HS rats were reduced. PrRP acts as an anorexigen, which is mediated by CRH neurons in the parvocellular PVN (Lawrence et al. 2004). Negative energy balance (e.g. food restriction, lactation) therefore downregulates the expression of PrRP (Lawrence et al. 2000). In dehydration-induced anorexia, however, central mechanisms might be turned on to reduce food intake, which is a way to compensate the excessive salt intake (Boyle et al. 2012). Thus, expression of PrRP is expected to be increased, which is in harmony with our results.

In the magnocellular PVN and SON, PrRP innervation was weak, but inducible by HS intake. PrRP-Rs were present barely. Still, a single dose of icv. PrRP is able to stimulate the release of magnocellular oxytocin and AVP (Maruyama et al. 1999; Uchida et al. 2010). As oxytocin regulates natriuresis and AVP regulates water conservation by the kidneys as well as increases blood pressure, both hormones substantially control the hypernatremia-evoked responses. Although direct action of PrRP mainly on oxytocin neurons is possible (Maruyama et al. 1999), our data indicate that PrRP stimulates hormone release from the magnocellular neurons via an indirect pathway.

We recognized the AV3V as a new site for PrRP's action. The AV3V exhibited a significant amount of PrRP-Rs and a great network of PrRP-positive fibers. In addition, PrRP innervation of the MnPO was enhanced by HS intake. The AV3V supervises the release of AVP and oxytocin (Honda et al. 1990; Yamaguchi and Yamada 2008; Tanaka et al. 1997) and plays a decisive role in the processing of autonomic responses elicited by HS intake (Pedrino et al. 2005; Bourque 2008). Therefore, it may serve as a relay center toward the magnocellular system. The effect of PrRP on the blood pressure (Samson et al. 2000; Yamada et al. 2009) was shown to be greatly mediated by neuropeptide FF2 receptors in the parvocellular PVN (Ma et al. 2009). However, according to our data the AV3V may also mediate this action via PrRP-Rs. Indeed, a polymorphism of the PrRP-R, the only cognate receptor of PrRP, has been associated with lower blood pressure in humans (Bhattacharyya et al. 2003).

In summary, we have found that the level of stress caused by chronic hypernatremia depended on the type of hypernatremia, affected the responsiveness to acute restraint differentially, and that the sensitivity of the HPA 
axis to acute restraint was reflected by the expression pattern in the cVLM. An interaction of NE and PrRP of medullary origin in the hypothalamus (PVN, SON, AV3V) in response to chronic hypernatremia was revealed and the AV3V was identified as a new site for PrRP's action.

Acknowledgements Open access funding provided by Semmelweis University (SE). Special thanks for Judit Kerti and Szilvia Deak for their technical contribution to the study.

Funding This work was supported by NKFIH K 115422 (ZET) and NKFIH K 120311 (ZD) and the Excellence Program (Semmelweis University).

\section{Compliance with ethical standards}

Conflict of interest The authors declare that they have no conflict of interest.

Ethics approval This article does not contain any studies with human participants performed by any of the authors. All applicable international, national, and/or institutional guidelines for the care and use of animals were followed. All procedures performed in studies involving animals were in accordance with the ethical standards of the institution or practice at which the studies were conducted. Experiments were performed according to the European Communities Council Directive (86/609/EEC/2 and 2010/63/EU) and were supervised by the Animal Care and Use Committee of the Institute of Experimental Medicine, Hungarian Academy of Sciences, Budapest, Hungary (22.1/3895/003/2009 and 22.1/533/3/2011) and Semmelweis University (PEl/001/1775-2/2015 and PE/EA/1563-7/2017) in accordance with legal requirements of the European Community (Decree 86/609/ EEC).

Open Access This article is licensed under a Creative Commons Attribution 4.0 International License, which permits use, sharing, adaptation, distribution and reproduction in any medium or format, as long as you give appropriate credit to the original author(s) and the source, provide a link to the Creative Commons licence, and indicate if changes were made. The images or other third party material in this article are included in the article's Creative Commons licence, unless indicated otherwise in a credit line to the material. If material is not included in the article's Creative Commons licence and your intended use is not permitted by statutory regulation or exceeds the permitted use, you will need to obtain permission directly from the copyright holder. To view a copy of this licence, visit http://creativecommons.org/licenses/by/4.0/.

\section{References}

Amaya F, Tanaka M, Hayashi S, Tanaka Y, Ibata Y (2001) Hypothalamo-pituitary-adrenal axis sensitization after chronic salt loading. Neuroendocrinology 73(3):185-193. https://doi. org/10.1159/000054635

Antoni FA (1993) Vasopressinergic control of pituitary adrenocorticotropin secretion comes of age. Front Neuroendocrinol 14(2):76-122. https://doi.org/10.1006/frne.1993.1004

Bhattacharyya S, Luan J, Challis B, Schmitz C, Clarkson P, Franks PW, Middelberg R, Keogh J, Farooqi IS, Montague C, Brennand J, Wareham NJ, O'Rahilly S (2003) Association of polymorphisms in GPR10, the gene encoding the prolactin-releasing peptide receptor with blood pressure, but not obesity, in a UK Caucasian population. Diabetes 52(5):1296-1299

Bienkowski MS, Rinaman L (2008) Noradrenergic inputs to the paraventricular hypothalamus contribute to hypothalamic-pituitaryadrenal axis and central Fos activation in rats after acute systemic endotoxin exposure. Neuroscience 156(4):1093-1102. https://doi.org/10.1016/j.neuroscience.2008.08.011

Bourque CW (2008) Central mechanisms of osmosensation and systemic osmoregulation. Nat Rev Neurosci 9(7):519-531. https:// doi.org/10.1038/nrn2400

Boyle CN, Lorenzen SM, Compton D, Watts AG (2012) Dehydration-anorexia derives from a reduction in meal size, but not meal number. Physiol Behav 105(2):305-314. https://doi. org/10.1016/j.physbeh.2011.08.005

Bundzikova J, Pirnik Z, Zelena D, Mikkelsen JD, Kiss A (2008) Response of substances co-expressed in hypothalamic magnocellular neurons to osmotic challenges in normal and Brattleboro rats. Cell Mol Neurobiol 28(8):1033-1047. https://doi. org/10.1007/s10571-008-9306-x

Chan RK, Peto CA, Sawchenko PE (1995) A1 catecholamine cell group: fine structure and synaptic input from the nucleus of the solitary tract. J Comp Neurol 351(1):62-80. https://doi. org/10.1002/cne. 903510107

Chen C, Dun SL, Dun NJ, Chang JK (1999) Prolactin-releasing peptide-immunoreactivity in $\mathrm{A} 1$ and $\mathrm{A} 2$ noradrenergic neurons of the rat medulla. Brain Res 822(1-2):276-279

Chen CC, Wada K, Jarvis ED (2012) Radioactive in situ hybridization for detecting diverse gene expression patterns in tissue. J Vis Exp. https://doi.org/10.3791/3764

Choe KY, Han SY, Gaub P, Shell B, Voisin DL, Knapp BA, Barker PA, Brown CH, Cunningham JT, Bourque CW (2015) High salt intake increases blood pressure via BDNF-mediated downregulation of KCC2 and impaired baroreflex inhibition of vasopressin neurons. Neuron 85(3):549-560. https://doi.org/10.1016/j. neuron.2014.12.048

Daubner SC, Le T, Wang S (2011) Tyrosine hydroxylase and regulation of dopamine synthesis. Arch Biochem Biophys 508(1):112. https://doi.org/10.1016/j.abb.2010.12.017

Day TA (1989) Control of neurosecretory vasopressin cells by noradrenergic projections of the caudal ventrolateral medulla. Prog Brain Res 81:303-317

Dayas CV, Buller KM, Crane JW, Xu Y, Day TA (2001) Stressor categorization: acute physical and psychological stressors elicit distinctive recruitment patterns in the amygdala and in medullary noradrenergic cell groups. Eur J Neurosci 14(7):11431152. https://doi.org/10.1046/j.0953-816x.2001.01733.x

da Silva EF, Freiria-Oliveira AH, Custodio CH, Ghedini PC, Bataus LA, Colombari E, de Castro CH, Colugnati DB, Rosa DA, Cravo SL, Pedrino GR (2013) A1 noradrenergic neurons lesions reduce natriuresis and hypertensive responses to hypernatremia in rats. PloS One 8(9):e73187. https://doi.org/10.1371/journ al.pone. 0073187

Dos Santos Moreira MC, Naves LM, Marques SM, Silva EF, Rebelo AC, Colombari E, Pedrino GR (2017) Neuronal circuits involved in osmotic challenges. Physiol Res 66(3):411-423

Dunkley PR, Bobrovskaya L, Graham ME, von Nagy-Felsobuki EI, Dickson PW (2004) Tyrosine hydroxylase phosphorylation: regulation and consequences. J Neurochem 91(5):1025-1043. https://doi.org/10.1111/j.1471-4159.2004.02797.x

Durst M, Konczol K, Balazsa T, Eyre MD, Toth ZE (2019) Rewardrepresenting D1-type neurons in the medial shell of the accumbens nucleus regulate palatable food intake. Int J Obes (Lond) 43(4):917-927. https://doi.org/10.1038/s41366-018-0133-y

Fernandez-Galaz C, Dyer RG, Herbison AE (1994) Analysis of brainstem $\mathrm{A} 1$ and $\mathrm{A} 2$ noradrenergic inputs to the preoptic area using microdialysis in the rat. Brain Res 636(2):227-232 
Flak JN, Myers B, Solomon MB, McKlveen JM, Krause EG, Herman JP (2014) Role of paraventricular nucleus-projecting norepinephrine/epinephrine neurons in acute and chronic stress. Eur J Neurosci 39(11):1903-1911. https://doi.org/10.1111/ejn.12587

Foo KS, Brismar H, Broberger C (2008) Distribution and neuropeptide coexistence of nucleobindin-2 mRNA/nesfatin-like immunoreactivity in the rat CNS. Neuroscience 156(3):563-579. https://doi.org/10.1016/j.neuroscience.2008.07.054

Gaillet S, Lachuer J, Malaval F, Assenmacher I, Szafarczyk A (1991) The involvement of noradrenergic ascending pathways in the stress-induced activation of ACTH and corticosterone secretions is dependent on the nature of stressors. Exp Brain Res 87(1): 173-180

Grinevich V, Ma XM, Verbalis J, Aguilera G (2001) Hypothalamic pituitary adrenal axis and hypothalamic-neurohypophyseal responsiveness in water-deprived rats. Exp Neurol 171(2):329_ 341. https://doi.org/10.1006/exnr.2001.7784

Guillaume V, Conte-Devolx B, Szafarczyk A, Malaval F, Pares-Herbute N, Grino M, Alonso G, Assenmacher I, Oliver C (1987) The corticotropin-releasing factor release in rat hypophysial portal blood is mediated by brain catecholamines. Neuroendocrinology 46(2):143-146. https://doi.org/10.1159/000124811

Harbuz MS, Rees RG, Eckland D, Jessop DS, Brewerton D, Lightman SL (1992) Paradoxical responses of hypothalamic corticotropin-releasing factor (CRF) messenger ribonucleic acid (mRNA) and CRF-41 peptide and adenohypophysial proopiomelanocortin mRNA during chronic inflammatory stress. Endocrinology 130(3):1394-1400. https://doi.org/10.1210/ endo.130.3.1537299

Haycock JW (1993) Multiple signaling pathways in bovine chromaffin cells regulate tyrosine hydroxylase phosphorylation at Ser19, Ser31, and Ser40. Neurochem Res 18(1):15-26

Hochstenbach SL, Ciriello J (1995) Plasma hypernatremia induces c-fos activity in medullary catecholaminergic neurons. Brain Res 674(1):46-54

Honda K, Negoro H, Dyball RE, Higuchi T, Takano S (1990) The osmoreceptor complex in the rat: evidence for interactions between the supraoptic and other diencephalic nuclei. J Physiol 431:225-241

Huang W, Sved AF, Stricker EM (2000) Vasopressin and oxytocin release evoked by $\mathrm{NaCl}$ loads are selectively blunted by area postrema lesions. Am J Physiol Regul Integr Comp Physiol 278(3):R732740. https://doi.org/10.1152/ajpregu.2000.278.3.R732

Khan AM, Kaminski KL, Sanchez-Watts G, Ponzio TA, Kuzmiski JB, Bains JS, Watts AG (2011) MAP kinases couple hindbrainderived catecholamine signals to hypothalamic adrenocortical control mechanisms during glycemia-related challenges. J Neurosci 31(50):18479-18491. https://doi.org/10.1523/jneur osci.4785-11.2011

Kitayama I, Cintra A, Janson AM, Fuxe K, Agnati LF, Eneroth P, Aronsson M, Harfstrand A, Steinbush HW, Visser TJ et al (1989) Chronic immobilization stress: evidence for decreases of 5-hydroxy-tryptamine immunoreactivity and for increases of glucocorticoid receptor immunoreactivity in various brain regions of the male rat. J Neural Transm 77(2-3):93-130

Konczol K, Bodnar I, Zelena D, Pinter O, Papp RS, Palkovits M, Nagy GM, Toth ZE (2010) Nesfatin-1/NUCB2 may participate in the activation of the hypothalamic-pituitary-adrenal axis in rats. Neurochem Int 57(3):189-197. https://doi.org/10.1016/j.neuin t.2010.04.012

Krause EG, Pati D, Frazier CJ (2017) Chronic salt-loading reduces basal excitatory input to $\mathrm{CRH}$ neurons in the paraventricular nucleus and accelerates recovery from restraint stress in male mice. Physiol Behav 176:189-194. https://doi.org/10.1016/j.physb eh.2017.03.038
Lawrence CB, Celsi F, Brennand J, Luckman SM (2000) Alternative role for prolactin-releasing peptide in the regulation of food intake. Nat Neurosci 3(7):645-646. https://doi.org/10.1038/76597

Lawrence CB, Liu YL, Stock MJ, Luckman SM (2004) Anorectic actions of prolactin-releasing peptide are mediated by corticotropin-releasing hormone receptors. Am J Physiol Regul Integr Comp Physiol 286(1):R101-107. https://doi.org/10.1152/ajpre gu.00402.2003

Liposits Z, Sherman D, Phelix C, Paull WK (1986) A combined light and electron microscopic immunocytochemical method for the simultaneous localization of multiple tissue antigens. Tyrosine hydroxylase immunoreactive innervation of corticotropin releasing factor synthesizing neurons in the paraventricular nucleus of the rat. Histochemistry 85(2):95-106

Ma XM, Lightman SL (1998) The arginine vasopressin and corticotrophin-releasing hormone gene transcription responses to varied frequencies of repeated stress in rats. J Physiol 510(Pt 2):605-614

Ma XM, Levy A, Lightman SL (1997) Emergence of an isolated arginine vasopressin (AVP) response to stress after repeated restraint: a study of both AVP and corticotropin-releasing hormone messenger ribonucleic acid (RNA) and heteronuclear RNA. Endocrinology 138(10):4351-4357. https://doi.org/10.1210/ endo.138.10.5446

Ma L, MacTavish D, Simonin F, Bourguignon JJ, Watanabe T, Jhamandas JH (2009) Prolactin-releasing peptide effects in the rat brain are mediated through the Neuropeptide FF receptor. Eur J Neurosci 30(8):1585-1593. https://doi.org/10.111 1/j.1460-9568.2009.06956.x

Maejima Y, Sedbazar U, Suyama S, Kohno D, Onaka T, Takano E, Yoshida N, Koike M, Uchiyama Y, Fujiwara K, Yashiro T, Horvath TL, Dietrich MO, Tanaka S, Dezaki K, Oh IS, Hashimoto K, Shimizu H, Nakata M, Mori M, Yada T (2009) Nesfatin-1-regulated oxytocinergic signaling in the paraventricular nucleus causes anorexia through a leptin-independent melanocortin pathway. Cell Metab 10(5):355-365. https://doi.org/10.1016/j.cmet.2009.09.002

Maruyama M, Matsumoto H, Fujiwara K, Noguchi J, Kitada C, Hinuma S, Onda H, Nishimura O, Fujino M, Higuchi T, Inoue K (1999) Central administration of prolactin-releasing peptide stimulates oxytocin release in rats. Neurosci Lett 276(3):193-196

Maruyama M, Matsumoto H, Fujiwara K, Noguchi J, Kitada C, Fujino M, Inoue K (2001) Prolactin-releasing peptide as a novel stress mediator in the central nervous system. Endocrinology 142(5):2032-2038. https://doi.org/10.1210/endo.142.5.8118

Menani JV, Vieira AA, Colombari DSA, De Paula PM, Colombari E, De Luca LA, Jr. (2014) Frontiers in Neuroscience PreopticPeriventricular Integrative Mechanisms Involved in Behavior, Fluid-Electrolyte Balance, and Pressor Responses. In: De Luca LA, Jr., Menani JV, Johnson AK (eds) Neurobiology of Body Fluid Homeostasis: Transduction and Integration. CRC Press/ Taylor \& Francis (c) 2014 by Taylor \& Francis Group, LLC., Boca Raton (FL),

Mera T, Fujihara H, Kawasaki M, Hashimoto H, Saito T, Shibata M, Saito J, Oka T, Tsuji S, Onaka T, Ueta Y (2006) Prolactinreleasing peptide is a potent mediator of stress responses in the brain through the hypothalamic paraventricular nucleus. Neuroscience 141(2):1069-1086. https://doi.org/10.1016/j.neuroscien ce. 2006.04 .023

Mezey E, Eisenhofer G, Hansson S, Hunyady B, Hoffman BJ (1998) Dopamine produced by the stomach may act as a paracrine/autocrine hormone in the rat. Neuroendocrinology 67(5):336-348. https://doi.org/10.1159/000054332

Mimee A, Smith PM, Ferguson AV (2012) Nesfatin-1 influences the excitability of neurons in the nucleus of the solitary tract and regulates cardiovascular function. Am J Physiol Regul Integr Comp Physiol 302(11):R1297-1304. https://doi.org/10.1152/ ajpregu.00266.2011 
Ong LK, Sominsky L, Dickson PW, Hodgson DM, Dunkley PR (2012) The sustained phase of tyrosine hydroxylase activation in vivo. Neurochem Res 37(9):1938-1943. https://doi.org/10.1007/s1106 4-012-0812-3

Pacak K, Palkovits M, Kopin IJ, Goldstein DS (1995) Stress-induced norepinephrine release in the hypothalamic paraventricular nucleus and pituitary-adrenocortical and sympathoadrenal activity: in vivo microdialysis studies. Front Neuroendocrinol 16(2):89-150. https://doi.org/10.1006/frne.1995.1004

Palkovits M (1973) Isolated removal of hypothalamic or other brain nuclei of the rat. Brain Res 59:449-450. https://doi. org/10.1016/0006-8993(73)90290-4

Paxinos G, Watson C (2007) The rat brain in stereotaxic coordinates, 6th edn. Elsevier, London, Amsterdam

Pedrino GR, Nakagawa Sera CT, Cravo SL, Colombari DS (2005) Anteroventral third ventricle lesions impair cardiovascular responses to intravenous hypertonic saline infusion. Auton Neurosci Basic Clin 117(1):9-16. https://doi.org/10.1016/j.autne u.2004.09.005

Pedrino GR, Rosa DA, Korim WS, Cravo SL (2008) Renal sympathoinhibition induced by hypernatremia: involvement of A1 noradrenergic neurons. Auton Neurosci Basic Clin 142(1-2):55-63. https ://doi.org/10.1016/j.autneu.2008.06.006

Pedrino GR, Freiria-Oliveira AH, Almeida Colombari DS, Rosa DA, Cravo SL (2012) A2 noradrenergic lesions prevent renal sympathoinhibition induced by hypernatremia in rats. PloS One 7(5): 37587

Pouzet B, Serradeil-Le Gal C, Bouby N, Maffrand JP, Le Fur G, Bankir L (2001) Selective blockade of vasopressin V2 receptors reveals significant V2-mediated water reabsorption in Brattleboro rats with diabetes insipidus. Nephrol Dial Transpl 16(4):725-734

Price CJ, Hoyda TD, Samson WK, Ferguson AV (2008) Nesfatin-1 influences the excitability of paraventricular nucleus neurones. J Neuroendocrinol 20(2):245-250. https://doi.org/10.111 $1 /$ j.1365-2826.2007.01641.x

Ritter S, Watts AG, Dinh TT, Sanchez-Watts G, Pedrow C (2003) Immunotoxin lesion of hypothalamically projecting norepinephrine and epinephrine neurons differentially affects circadian and stressor-stimulated corticosterone secretion. Endocrinology 144(4):1357-1367. https://doi.org/10.1210/en.2002-221076

Roland BL, Sutton SW, Wilson SJ, Luo L, Pyati J, Huvar R, Erlander MG, Lovenberg TW (1999) Anatomical distribution of prolactinreleasing peptide and its receptor suggests additional functions in the central nervous system and periphery. Endocrinology 140(12):5736-5745. https://doi.org/10.1210/endo.140.12.7211

Samson WK, Resch ZT, Murphy TC (2000) A novel action of the newly described prolactin-releasing peptides: cardiovascular regulation. Brain Res 858(1):19-25

Sawchenko PE, Swanson LW (1981) Central noradrenergic pathways for the integration of hypothalamic neuroendocrine and autonomic responses. Science 214(4521):685-687

Sawchenko PE, Swanson LW (1982) The organization of noradrenergic pathways from the brainstem to the paraventricular and supraoptic nuclei in the rat. Brain Res 257(3):275-325

Scholer J, Sladek JR Jr (1981) Supraoptic nucleus of the Brattleboro rat has an altered afferent noradrenergic input. Science 214(4518):347-349

Seal LJ, Small CJ, Dhillo WS, Kennedy AR, Ghatei MA, Bloom SR (2002) Prolactin-releasing peptide releases corticotropin-releasing hormone and increases plasma adrenocorticotropin via the paraventricular nucleus of the hypothalamus. Neuroendocrinology 76(2):70-78. https://doi.org/10.1159/000064427

Sterrenburg L, Borch A, Peeters BW, Pinter O, Zelena D, Roubos EW, Kozicz T (2011) Acute ether stress differentially affects corticotropin-releasing factor and urocortin 1 in the Brattleboro rat. Brain Res 1398:21-29. https://doi.org/10.1016/j.brainres.2011.04.047
Sun Z (2006) Genetic AVP deficiency abolishes cold-induced diuresis but does not attenuate cold-induced hypertension. Am J Physiol Renal Physiol 290(6):F1472-1477. https://doi.org/10.1152/ajpre nal.00430.2005

Szafarczyk A, Alonso G, Ixart G, Malaval F, Assenmacher I (1985) Diurnal-stimulated and stress-induced ACTH release in rats is mediated by ventral noradrenergic bundle. Am J Physiol 249(2 Pt 1):E219-226. https://doi.org/10.1152/ajpendo.1985.249.2.E219

Tanaka J, Hayashi Y, Watai T, Fukami Y, Johkoh R, Shimamune S (1997) A1 noradrenergic modulation of AV3V inputs to PVN neurosecretory cells. Neuroreport 8(14):3147-3150

Toth ZE, Mezey E (2007) Simultaneous visualization of multiple antigens with tyramide signal amplification using antibodies from the same species. J Histochem Cytochem 55(6):545-554. https://doi. org/10.1369/jhc.6A7134.2007

Toth ZE, Gallatz K, Fodor M, Palkovits M (1999) Decussations of the descending paraventricular pathways to the brainstem and spinal cord autonomic centers. J Comp Neurol 414(2):255-266

Toth ZE, Zelena D, Mergl Z, Kirilly E, Varnai P, Mezey E, Makara GB, Palkovits M (2008) Chronic repeated restraint stress increases prolactin-releasing peptide/tyrosine-hydroxylase ratio with genderrelated differences in the rat brain. J Neurochem 104(3):653-666. https://doi.org/10.1111/j.1471-4159.2007.05069.x

Uchida K, Kobayashi D, Das G, Onaka T, Inoue K, Itoi K (2010) Participation of the prolactin-releasing peptide-containing neurones in caudal medulla in conveying haemorrhagic stressinduced signals to the paraventricular nucleus of the hypothalamus. J Neuroendocrinol 22(1):33-42. https://doi.org/10.111 1/j.1365-2826.2009.01935.x

Ulrich-Lai YM, Herman JP (2009) Neural regulation of endocrine and autonomic stress responses. Nat Rev Neurosci 10(6):397-409. https://doi.org/10.1038/nrn2647

Varga J, Ferenczi S, Kovacs KJ, Csano A, Prokopova B, Jezova D, Zelena D (2016) Dissociation of adrenocorticotropin and corticosterone as well as aldosterone secretion during stress of hypoglycemia in vasopressin-deficient rats. Life Sci 166:66-74. https ://doi.org/10.1016/j.lfs.2016.10.011

Vas S, Adori C, Konczol K, Katai Z, Pap D, Papp RS, Bagdy G, Palkovits M, Toth ZE (2013) Nesfatin-1/NUCB2 as a potential new element of sleep regulation in rats. PloS One 8(4):e59809. https ://doi.org/10.1371/journal.pone.0059809

Wittmann G, Mohacsik P, Balkhi MY, Gereben B, Lechan RM (2015) Endotoxin-induced inflammation down-regulates L-type amino acid transporter 1 (LAT1) expression at the blood-brain barrier of male rats and mice. Fluids Barriers CNS 12:21. https://doi. org/10.1186/s12987-015-0016-8

Yamada T, Mochiduki A, Sugimoto Y, Suzuki Y, Itoi K, Inoue K (2009) Prolactin-releasing peptide regulates the cardiovascular system via corticotrophin-releasing hormone. J Neuroendocrinol 21(6):586-593. https://doi.org/10.1111/j.1365-2826.2009.01875.x

Yamaguchi K, Yamada T (2008) Roles of forebrain GABA receptors in controlling vasopressin secretion and related phenomena under basal and hyperosmotic circumstances in conscious rats. Brain Res Bull 77(1):61-69. https://doi.org/10.1016/j.brainresbu 11.2008.04.009

Yang Z, Coote JH (2007) Paraventricular nucleus influence on renal sympathetic activity in vasopressin gene-deleted rats. Exp Physiol 92(1):109-117. https://doi.org/10.1113/expphysiol.2006.034884

Yilmaz MS, Altinbas B, Guvenc G, Erkan LG, Avsar O, Savci V, Kucuksen DU, Arican I, Yalcin M (2015) The role of centrally injected nesfatin-1 on cardiovascular regulation in normotensive and hypotensive rats. Auton Neurosci Basic Clin 193:63-68. https ://doi.org/10.1016/j.autneu.2015.07.009

Yosten GL, Samson WK (2009) Nesfatin-1 exerts cardiovascular actions in brain: possible interaction with the central melanocortin 
system. Am J Physiol Regul Integr Comp Physiol 297(2):R330 336. https://doi.org/10.1152/ajpregu.90867.2008

Zelena D, Mergl Z, Foldes A, Kovacs KJ, Toth Z, Makara GB (2003)

Role of hypothalamic inputs in maintaining pituitary-adrenal responsiveness in repeated restraint. Am J Physiol Endocrinol Metab 285(5):E1110-1117. https://doi.org/10.1152/ajpen do.00219.2003
Publisher's Note Springer Nature remains neutral with regard to jurisdictional claims in published maps and institutional affiliations. 